\title{
Suero lácteo, generalidades y potencial uso como fuente de calcio de alta biodisponibilidad
}

\author{
Whey, generalities and potential \\ use as source of calcium from \\ high bioavailability
}

\begin{abstract}
The whey is defined as a dairy product obtained during the manufacturing of cheese. It is not a substitute for cow's milk because it is a fraction of it. However, the whey contains nutrients and compounds with potential nutritional and functional benefits. Approximately $90 \%$ of calcium from milk is present in whey. Some scientific evidence suggests that calcium from whey is more bioavailable, even overpassing the mineral salts that are used for food fortification or nutritional supplements. The enhanced bioavailability is associated with the nutrients present within, especially proteins and lactose. It has also been shown that the technology used for the processing of whey can involve greater or lesser concentration and bioavailability of calcium. Human Investigations are needed to confirm these hypotheses.

Key words: whey, calcium, bioavailibity, lactose, proteins from whey, ultrafiltration.
\end{abstract}

Elpidia Poveda E.

Área de Nutrición y Salud, Instituto Alpina de Investigación, Colombia.

Dirigir la correspondencia a: Dra. Elpidia Poveda Área de Nutrición y Salud Instituto Alpina de Investigación Instituto Alpina de Investigación
Corporativo, Km. 3 vía Briceño-Sopó Sopó-Cundinamarca-Colombia Tel: (57-1) 4238600 Ext. 1569/ E-mail: elpidia.poveda@alpina.com.co

Este trabajo fue recibido el 15 de Enero de 2013. aceptado con modificaciones el 1 de Mayo de 2013 y aceptado para ser publicado el 5 de septiembre de 2013.
El lactosuero o suero de leche se define como un producto lácteo obtenido de la separación del coágulo de la leche, de la crema o de la leche semidescremada durante la fabricación del queso, mediante la acción ácida o de enzimas del tipo del cuajo (renina, enzima digestiva de los rumiantes) $(1,2)$ que rompen el sistema coloidal de la leche en dos fracciones: 1). Una fracción sólida, compuesta principalmente por proteínas insolubles y lípidos, las cuales en su proceso de precipitación arrastran y atrapan minoritariamente algunos de los constituyentes hidrosolubles. 2) Una fracción líquida, correspondiente al lactosuero en cuyo interior se encuentran suspendidos todos los otros componentes nutricionales que no fueron integrados a la coagulación de la caseína $(3,5)$. De esta forma, se encuentran en el lactusuero partículas suspendidas solubles y no solubles (proteínas, lípidos, carbohidratos, vitaminas y minerales), y compuestos de importancia biológica-funcional $(6,7)$.

El suero en consecuencia, no constituye un sustituto integral de la leche de vaca por ser una fracción de la misma, pero contiene nutrientes y compuestos con potenciales beneficios nutricionales y de salud que se aprovechan en algunos países para la fabricación de productos alimenticios y suplementos, o como materia prima para la producción de otros ingredientes, y compuestos. Se observan algunas aplicaciones industriales del suero en la tabla 1.

La producción mundial anual de lactusuero en el año
2011 se estimó en más de 145 millones de toneladas, siendo los principales productores Estados Unidos y la Unión Europea (primordialmente Alemania, Francia, e Italia) con aproximadamente el $70 \%$ de la producción mundial $(8,9)$. Este aumento en la producción parece estar asociado al incremento en la producción de queso y productos lácteos per se y a los avances científicos y tecnológicos para la recuperación de los subproductos del suero (10-14).

Sin embargo, a pesar del valor nutricional potencial del suero y al aumento en su aprovechamiento para la producción de otros alimentos, aún gran parte es descartado, causando problemas de contaminación en ríos y suelos $(8,10,15)$. La eliminación del suero se debe entre otros aspectos, al desconocimiento de algunos productores sobre las bondades nutricionales de este subproducto y a la dificultad para acceder a las tecnologías apropiadas para su manejo y procesamiento; también, a limitaciones en la regulación alimentaria que permitan la apropiada utilización como ingrediente alimenticio.

Por otra parte, aunque la producción de suero y la producción y suministro de productos lácteos y derivados han incrementado, el consumo (y la ingesta de calcio) sigue siendo bajo en la mayoría de los países, en comparación con las cantidades recomendadas (16). Esta situación puede asociarse a hábitos de alimentación inadecuados (17) y al costo de adquirir productos lácteos, especialmente en países donde no 
existen políticas claras que favorezcan de manera accequible la producción de alimentos lácteos )(18,19).

La utilización del suero como una alternativa para incrementar el contenido de calcio en los alimentos podría además de ser otra opción de uso y comercialización del suero, contribuir en alguna medida a proporcionar calcio de mayor biodisponibilidad, sea para alimentos de base láctea o de otro tipo de productos. Asimismo, una opción para incrementar el consumo de calcio posiblemente más accequible para las personas vs de la leche integra, productos fortificados con calcio mineral o suplementos

El objetivo de este artículo es realizar una revisión relacionada con la composición general del lactusuero, su contenido de calcio y los posibles factores asociados a su biodisponibilidad, entendida esta última como la fracción de calcio potencialmente absorbible por el intestino y usada para realizar las funciones fisiológicas, particularmente, para la mineralización ósea y la reducción de la pérdida ósea (20).

COMPOSICIÓN NUTRICIONAL DEL LACTUSUERO

La composición nutricional del lactosuero puede variar considerablemente dependiendo de las características de la leche utilizada para la elaboración del queso, el tipo de queso producido y del proceso de tecnología empleado en la elaboración del queso. A partir de estas diferencias se encuentran dos tipos fundamentales de lactusuero: 1) Suero dulce, cuando se produce a partir de acción enzimática y contiene más lactosa. 2) Suero ácido, aquel que se obtiene por acción ácida, con mayor concentración de proteínas (21). En la tabla 2 se puede observar la composición general del suero y su distribución proteica.

En cuanto a minerales, el lactosuero puede contener aproximadamente el $90 \%$ del calcio, potasio, fósforo, sodio y magnesio presente en la leche (tabla 2) $(4,21)$. Estos minerales se transfieren al suero o a los permeados después de la coagulación de la proteína en la producción de la cuajada (22). Investigaciones hechas en ratas evidencian que el calcio lácteo presente en la fracción del suero puede ser incluso más biodisponible en comparación con algunas fuentes de calcio utilizadas comercialmente como suplementos, entre ellas se mencionan, el carbonato de calcio, el citrato de calcio y el lactato de calcio $(23,24)$.

El suero lácteo también contiene compuestos biológicamente activos y péptidos bioactivos definidos, como

TABLA 1

Composición general del suero y distribución proteica.

Componente

Lactosa

Proteína

a-Lactoalbumina

$\beta$-Lactoglobulina

Globulina

Proteasas-peptonas

Lípidos

Vitaminas

Minerales

Compuestos biológicamente activos y péptidos bioactivos
Observaciones

95\% de la lactosa de la leche, en una proporción de (4,5-5,0 \% p-v). ). 46,0-52,0 g/L en lactusuero dulce y 44,00-46,0 de lactusuero ácido.

En una proporción $0,8-1,0 \%$ p/v. Corresponde alrededor del 25\% de las proteínas contenidas normalmente en la leche. $6,0 \mathrm{~g} / \mathrm{l}$ en lactusuero dulce y 6,0-8,0 g/l en lactusuero ácido. Alto contenido de aminoácidos (Leucina, isolecucina, licina, valina) vs proteínas de referencia, caseína, proteína de soya y proteína humana.

$30 \%$ del total del contenido proteico

Es importante porque tiene propiedades emulsionantes y cumple una función importante al interactuar con compuestos como el retinol y los ácidos grasos.

\section{Corresponden a $10 \%$ del total de proteínas}

Corresponden a $10 \%$ del total de proteínas. Lactoferrinas, albúmina (idéntica a la albúmina sérica de la sangre), inmunoglobulinas, factores de crecimiento, glicoproteínas y enzimas (nucleasas, lactoperoxidasas, xantina oxidasa, lipasa estearasa, amilasa, fosfatasas ácidas y alcalinas, lisozima, aldolasa, catalasa, inhibidor de la tripsina, lactosa sintetasa, ceruloplasmina, sulfidriloxidasa y otras) Son proteínas de alto valor biológico al proporcionar aminoácidos esenciales para el organismo, entre ellos, triptófano, leucina, e isoleucina (21), (67), (68), (70).

$0,5 \%$ y $8 \%$ de la materia grasa de la leche .

Tiamina 0,38mg/ml; Riboflavina 1,2mg/ml; Acido nicotínico 0,85 mg/ml Ácido Pantoténico 3,4mg/ml; Priridoxina 0,42 mg/ml; Cobalamina 0,03 mg/ml; Ácido ascórbico $2,2 \mathrm{mg} / \mathrm{ml}$

8-10\% del extracto seco. Calcio $(0,4-0,6 \mathrm{~g} / \mathrm{l}$ en lactusero dulce y $1,2-1,6 \mathrm{gl} /)$ en lactusuero ácido), potasio, fosforo, sodio y magnesio.

Para ejercer determinados efectos biológicos y fisiológicos. Con potencial antihipertensivo, actividad antimicrobial, antioxidante, incremento de la saciedad, entre otros. 
fragmentos específicos de proteínas, que tienen un impacto positivo sobre funciones o condiciones corporales y que pueden influir sobre la salud humana, más allá de una nutrición normal y adecuada. Estos péptidos son resistentes a la acción de peptidasas digestivas, lo que les permite su absorción y paso al torrente sanguíneo sin ninguna alteración estructural para ejercer determinados efectos biológicos y fisiológicos (25-27).

Se encuentran péptidos opioides principalmente de $\alpha$ lactoglobulina y de albumina sérica con efecto sobre el sistema nervioso e inhibición de la actividad de la ACE; péptidos inmunomoduladores que incrementan la actividad fagócitica de los macrófagos, y ejercen efectos antimicrobianos y antivirales; péptidos con efectos favorables sobre el sistema cardiovascular, vía antitrombótica, antihipertensiva e hipocolesterolemica y péptidos antioxidantes, entre otros (27-30).

\section{HOMEÓSTASIS DE CALCIO}

El intestino es el principal órgano por donde los iones de calcio ingresan a los compartimentos corporales, por consiguiente, la mucosa intestinal es prácticamente la única barrera biológica para que el calcio ingrese a la circulación portal, y a la circulación sistémica $(20,31,34)$.

El transporte del calcio a nivel intestinal involucra translocación de iones de calcio soluble mediante dos mecanismos de transporte presentes a nivel del lumen intestinal; el primero, referente al transporte activo en las células del duodeno y del yeyuno proximal (modelo celular), y el segundo, por difusión pasiva en el intestino delgado, principalmente en el íleo, y, en menor proporción en el intestino grueso (modelo paracelular). Para que el calcio sea soluble a nivel del intestino delgado y para que pueda atravesar la pared intestinal debe encontrarse

TABLA 2

Algunos usos del lactusuero en alimentos u otros.

$$
\text { Aplicaciones en }
$$

Productos de panadería como croissants, tortas

Productos lácteos como bebidas fermentadas y quesos.

Bebidas como jugos de fruta, refrescos, bebidas achocolatadas, bebidas a base de leche

Postres como barras de yogurt, helados

Confitería

Productos cárnicos

Alimentos nutricionales

Para concentrados de proteína

Para obtener aislados de proteína

Para obtener hidrolizados de proteína

Purificación de proteínas aisladas

Fuente de compuesto bioactivos

Fuente de lactosa

Fuente para extraer minerales
Algunos beneficios

Incrementar el valor nutricional, como emulsificante, reemplazar la adición de huevo, para dar cuerpo a la masa.

Valor nutricional, emulsificante, gelificante, mejorar propiedades organolépticas, mejorar consistencia, cohesividad.

Valor nutricional, solubilidad, viscosidad, estabilidad coloidal.

Propiedades emulsificantes, dar cuerpo y textura a los productos.

Como emulsificante y para facilitar el batido

Pre- emulsificante, gelificante, mejorar solubilidad

Alimentos de mayor valor nutricional y bajo costo, alimentos para deportistas, para personas adulto mayor, formulas nutricionales especiales para mantener peso saludable o aumentar consumo de proteína, fórmulas infantiles, fórmulas especiales para alimentación hospitalaria.

Para productos alimenticios especiales, suplementos nutricionales, productos de panadería y confitería. Contiene aproximadamente $25-89 \%$ de proteína, 4-52\% de lactosa y 1-9\% de grasa.

Para suplementos de proteína, bebidas y productos altos en proteína, Contiene aproximadamente $90-95 \%$ de proteína, 0,5-1\% de lactosa y $0,5-1 \%$ de grasa

Para fórmulas infantiles, productos para deportistas, productos nutricionales especiales. Contiene aproximadamente $80-90 \%$ de proteína, $0,5-1 \%$ de lactosa y $0,5-0,8 \%$ de grasa

a lactoalbuminas, $\beta$ Lactoglobulinas, inmunoglobulinas, glicoproteínas como lactoferrina y lactoperoxidasa.

Péptidos y proteínas con potencial antihipertensivo, actividad antimicrobial, antioxidante, incremento de la saciedad, etc.

Compuesto transportador en productos farmacéuticos, componente de fórmulas infantiles, materia prima para la producción de derivados de lactosa: lactulosa, GOS, lactitol, glucosa.

Para bioconverisòn de lactosa: Alcohol, ácido lactito, biocombustible.

Calcio, fósforo.

Ref: $(71,65)$ 
en forma ionizada $\left(\mathrm{Ca}^{++}\right)$o unido a moléculas orgánicas solubles (20,31-34).

La homeostasis del calcio está regulada por la concentración de iones de calcio soluble presentes en los compartimentos corporales extracelulares e intracelulares siguiente a la absorción en el trato gastrointestinal. En el modelo celular los iones de calcio son transportados vía compartimentos citosólicos y facilitado por la vitamin D. En la vía paracelular, no dependiente de vitamina $D$, ni modificable por la edad, los iones de calcio son movidos por las uniones estrechas entre las células adyacentes mediante absorción pasiva; esta vía involucra el movimiento de agua y solutos como sodio y glucosa. La tasa de transporte de calcio del mecanismo celular es saturable y alcanza un valor constante a una cierta concentración de calcio intraluminal. Alternativamente, la tasa de transporte de calcio en el modelo paracelular no es saturable, e incrementa como una función lineal de la concentración soluble del ion, es decir, incrementa con el consumo de calcio dietario soluble $(20,31,32)$.

Los factores de la leche que incrementan el transporte de calcio paracelular incluyen la caseína, la lactosa, el fósforo, algunos aminoácidos y compuestos bioactivos, como las caseinfosfopéptidos (CPP) de proteínas de leche (20). Algunos de estos compuestos presentes igualmente en el suero pueden contribuir a que el calcio de esta fracción de la leche sea un calcio biodisponible. Para el caso del lactusuero, otro factor que parece influir en la absorción del calcio es la tecnología utilizada en su producción industrial, dando un factor diferencial cuando se utilizan por ejemplo, tecnologías de ultrafiltración versus las de precipitación (35).

\section{LACTOSA}

Los efectos benéficos de la lactosa sobre la absorción del calcio es uno de los componentes de la leche que más se ha estudiado $(20,36,37,38)$. Inicialmente se pensó en que la lactosa así como otros azúcares podían actuar directamente sobre el hueso como precursores de proteínas óseas, sin embargo, esta idea cambió al observar efectos a nivel intestinal (39). Las soluciones de alta osmolaridad como las correspondientes a lactosa parecen ser absorbidas lentamente en el íleo, en los mismos sitios de absorción del calcio, prolongando de este modo, la absorción pasiva e independiente de vitamina D (40). Los estudios muestran que las soluciones de lactosa pueden llegar a doblar o triplicar la difusión pasiva, probablemente al incrementar la permeabilidad del calcio en el espacio de las uniones intercelulares $(40,41)$.

Otra razón por la cual se considera que la lactosa puede ayudar a absorber el calcio, es por su efecto competitivo con inhibidores de la absorción del calcio como los fosfatos: la lactosa como otros azúcares puede ser fosforilada al aceptar un grupo fosfato en una reacción catalizada por la fosfatasa alcalina, reduciendo así la inhibición por fosfatos dentro del lumen intestinal $(42,43)$

En otros estudios se observa que la lactosa y otros azúcares pueden incrementar la absorción de calcio en el yeyuno, proporcionalmente a sus efectos sobre la absorción de agua y sodio (44).

Se ha observado, no obstante, que en adultos sanos con dieta normal, las concentraciones de lactosa presentes regularmente en la leche no parecen afectar la absorción de calcio de manera significativa $(45,46)$ únicamente dosis altas parecen tener efectos benéficos, y al parecer puede ser dependiente de la actividad de la lactasa a nivel intestinal $(20,40,47,48)$. Resultados similares se han observado en estudios donde se evalúa la absorción de calcio de yogurt, en el cual la lactosa está parcialmente hidrolizada o en derivados lácteos que no contienen lactosa, observando que el calcio de estos alimentos se absorbe tan eficientemente como el de la leche $(49,50)$.

No obstante, cualquier efecto de la lactosa sobre la absorción pasiva podría estar enmascarado por el modelo de transporte activo que resulta suficiente para proveer el calcio requerido si la ingestión dietética de calcio es moderada y no hay deficiencia de vitamina $D$. Los beneficios de la lactosa sobre la absorción del calcio pueden llegar a ser más evidentes en los casos donde las necesidades de calcio son más elevadas, principalmente en los bebés, y, en los ancianos, donde la solubilidad es un factor limitante y la absorción pasiva pasa a ser la vía predominante. Asimismo, en aquellos casos donde pueda coexistir deficiencia de vitamina $D$ o ingesta deficiente de calcio.

En algunos individuos con deficiencia de lactasa o malabsorción de lactosa podrían existir alteraciones en la absorción del calcio. Griessen et al. encontraron como la lactosa incrementa la absorción de calcio en sujetos deficientes de lactasa contrario a otros estudios donde se observa un efecto contrario o ningún efecto $(36,47,51,52)$.

En otros estudios donde se evalúa la asimilación del calcio en personas deficientes de lactosa o normales vs el consumo de yogur pasteurizado o no pasteurizado se encuentra que en el caso del yogur pasteurizado, la asimilación de calcio es inferior a la de los sujetos que consumen yogur sin pasteurizar e independientemente de si las personas son deficientes en lactosa o no. Estas observaciones sugieren que la asimilación del calcio puede ser más favorable probablemente a partir de la presencia de cultivos vivos e independiente de si las personas son deficientes o no de lactasa (53).

\section{PROTEÍNAS DEL SUERO}

Estudios in vitro demuestran que las proteínas del suero, como la $\alpha$-lactoalbumina y la $\beta$-lactoglobulina, se pueden unir al calcio, interviniendo en su biodisponibilidad. La $\alpha$-lactoalbúmina se une fuertemente al calcio, de forma similar a la calmodulina, no obstante, estos efectos parecen ser menos evidentes in vivo $(20,54,55)$

Adicional a la relación entre las proteínas del suero, y el calcio presente en esta fracción láctea, se encuentra evidencia de que los componentes proteicos del suero, (refiriéndose con ello a la $\alpha$-lactoalbumina, $\beta$-lactoglobulina, albumina, inmunoglobulinas, y proteínas bioactivas presentes en menor proporción), pueden tener un impacto positivo sobre la salud ósea (56) porque estimulan el crecimiento y la diferenciación de células óseas in vitro y suprimen la resorción ósea en ratas ovariectomizadas (OVX) (57). La relación de estas proteínas con el metabolismo óseo en ratas OVX se asocia al aumento en el hueso de proteínas como el colágeno, a la mejora en la fuerza de rotura ósea (fuerza y energía), y a la activación de los osteoblastos (58).

Otros estudios realizados en ratas en crecimiento, muestran que la alimentación con un complejo de minerales de suero ácido de leche da como resultado una mayor densidad mineral ósea y una reducción en los niveles de hormona paratiroidea después de 28 días de su consumo (59). Entre los minerales, el contenido de fósforo y magnesio, pueden ser los factores más relevantes para una mejor absorción y utilización del calcio a nivel fisiológico.

TECNOLOGÍA DE PROCESAMIENTO

La tecnología de producción del queso no sólo determina 
la cantidad de componentes de la leche que son transferidos hacia el suero y permeados, sino también, su valor nutricional $(22,60,61)$. Existe evidencia de que las tecnologías utilizadas industrialmente para la obtención del suero pueden derivar en diferentes formas químicas del mineral, alterando así su biodisponibilidad. Se ha comprobado por ejemplo, que la forma química convencional del calcio del suero obtenido a través de métodos de neutralización y precipitación es del tipo hidroxiapatita, un compuesto de calcio menos biodisponible en comparación a las formas de calcio obtenidas mediante métodos de ultrafiltración. El método de ultrafiltración no permite la formación de los cristales del tipo hidroxiapatita, sino por el contrario, da origen a otro tipo de morfologías de calcio que en investigaciones con modelos animales muestran mejor biodisponibilidad al producir mayor taza de absorción, mayor contenido de calcio en el hueso del fémur, mayor requerimiento de fuerza para lograr una fractura ósea y menores concentraciones de paratohormona (PTH) en suero $(35,62)$.

En otros estudios en ratas se encuentra que el uso de procesos de nanofiltración y ultrafiltración en suero ácido no causa diferencias en el contenido de calcio, fosforo y otros minerales, mientras que la introducción de diafiltración a la nanofiltración disminuye los contenidos de calcio $(60,63)$.

En conclusión, es complejo para los individuos en general, consumir el calcio suficiente para mantener una adecuada salud ósea, por esto, es importante disponer de buenas fuentes de calcio biodisponible, en particular en personas con mayores necesidades de calcio, en individuos con dificultad para acceder a los alimentos fuente o en personas de edad que tienen una habilidad disminuida para absorber el nutriente, incrementando el riesgo de osteoporosis y fracturas óseas.

El suero lácteo por su contenido de calcio y por la composición de lactosa, proteínas, minerales u otros compuestos, así como por la tecnología de procesamiento para obtenerlo parece ser una alternativa conveniente y más natural para enriquecer con calcio de mayor biodisponibilidad a diferentes productos alimenticios, de hecho es hoy un ingrediente muy utilizado para mejorar las características sensoriales de los productos y a su vez el perfil nutricional. Al parecer la biodisponibilidad del calcio proveniente del suero, considerado como de origen orgánico y natural resulta superior al de las fuentes minerales usadas cotidianamente para incrementar el consumo de este micronutriente.

Es importante realizar estudios en humanos que den respuesta a los aspectos inconclusos y demuestren de manera concluyente los beneficios del suero como ingrediente fuente de calcio y como sub-producto con ventajas adicionales para la salud ósea. Las investigaciones deberían incluir comparaciones en relación a la leche integra, productos alimenticios fortificados y suplementos.

Igualmente, sería importante estudiar el comportamiento en diferentes matrices alimenticias, teniendo en cuenta, que las diferencias en su composición y reología pueden modificar la biodisponibilidad, por ejemplo, cuando el suero se utiliza como un ingrediente en productos de base láctea, cuando se le ha retirado parte de su contenido de lactosa, o cuando se adicionan otros micronutrientes como la vitamina $D$. Aunque el suero corresponde a una fracción de la leche integra y no la reemplaza desde el punto de vista de alimento, puede ofrecer beneficios nutricionales sensibles de estudiar y aprovechar en el desarrollo de alimentos novedosos con beneficios nutricionales y funcionales, especialmente sobre la salud ósea.

Otro aspecto importante es examinar las diferencias en los contenidos de calcio y en la biodisponibilidad del mineral de acuerdo al tipo de suero utilizado y a la tecnología usada para su procesamiento, es factible encontrar diferencias por las variaciones en composición, acidez del mismo y estructura del calcio. Además, estudios a partir de calcio aislado de suero.

\section{RESUMEN}

El lactosuero o suero de leche se define como un subproducto lácteo obtenido durante la fabricación del queso que aunque no constituye un sustituto integral de la leche de vaca por ser una fracción de la misma, contiene nutrientes y compuestos con potenciales beneficios nutricionales y funcionales. El calcio es uno de los nutrientes que puede estar en cantidades considerables, alcanzando hasta el $90 \%$ de la concentración inicial del mineral en la leche. Existe evidencia que el calcio del suero lácteo es de mayor biodisponibilidad, incluso superando a las sales minerales que se utilizan para fortificación de alimentos o como suplementos nutricionales. La mayor biodisponibilidad se asocia con el contenido de nutrientes presente en el mismo, especialmente proteínas y lactosa. También se ha demostrado que la tecnología utilizada para el procesamiento del suero puede implicar mayor o menor concentración y biodisponibilidad de calcio en suero. Se requieren investigaciones en humanos para confirmar estas hipótesis.

Palabras clave: lactusuero, calcio, biodisponibilidad, lactosa, proteínas del lactusuero, ultrafiltración.

\section{BIBLIOGRAFÍA}

1. SERVICES., FDA-DEPARTMENT OF HEALTH AND HUMAN. CFR - Code of Federal Regulations .TITLE 21- CHAPTER I.SUBCHAPTER B-PART 184.Sec. 184.1979 Whey. 2012. Disponible en http://www.accessdata.fda.gov/ scripts/cdrh/cfdocs/cfCFR/CFRSearch.cfm?fr=184.1979. Consultado en diciembre 2012. Title 21, Volume 3. CITE: 21CFR184.1979.

2. FAO AND WHO. Milk and milk product s (2nd Edition). CODEX STANDARD FOR WHEY POWDERS. CodeX STAN 289-1995. 1995. Disponible en www.codexalimentarius. org/input/.../standards/184/CXS_289s.pdf. Consultado Diciembre 2012.

3. Walstra P, Geurts $T$, Noomen A, Jellema A, van Boekel M. Ciencia de la leche y tecnología de los productos lácteos. 1a ed. Zaragoza : Editorial Acribia, 2001.

4. Walzem R, Dillard C, German J.Whey components: millennia of evolucion crete functionalities for mamalian nutrition: what we know and what we may be overlooking. Crit Rev Food Sci. 2002; 42:353-75.

5. Birsen Bulut Solak, Nihat Akın. Functionality of Whey Protein. Int J Health Nutr. 2012; 3:1-7.

6. Illanes, Andrés. Whey upgrading by enzyme biocatalysis. 2011, Electronic Journal of Biotechnology. Disponible en http://www.ejbiotechnology.info. Consultado Diciembre 2012.

7. Barth CA, Behnke U.Nutritional physiology of whey and whey components. Nahrung. 1997;41: 2-12. (Abstract).

8. FAO (Organización de las Naciones Unidas para la Alimentación y la Agricultura), FEPALE (Federación Panemericana de Lechería). Situación de la Lechería en América Latina y el Caribe en 2011. Observatorio de la Cadena Lechera. Oficina regional de la FAO para América Latina y el Caribe. Divisiñon de Producciòn y Sanidad animal. 2012.

9. USDA, NASS. Dairy products ( August 2013). National Agriculture Estatics service, USDA. 2013. ISSN 1949-0399.

10. Gupta, Vijay Kumar.Advances in Membrane Processing for 
Production of Novel Dairy Ingredients. Innovative Trends Dairy Food Products Formulation. 2012; 83; 1-232.

11. Arunima Saxena, BP Tripathi, M Kumar, VK Shahi. Membrane-based techniques for the separation and purification of proteins: An overview. Adv Colloid Interface Sci. 2009; 145(1-2): 1-22.

12. MC Michalski, N Leconte, V Briard-Bion. Microfiltration of raw whole milk to select fractions with different fat globule size distributions: Process Optimization analysis. J Dairy Sci 2006; 89 (10): 3778-90.

13. BAEl, Mazyar Sharifzadeh, Hosseinzadeh, Mohammad Javad y Younesi, Habibollah.. Whey Processing with Nano Chitosan. World Applied Sciences. 2012; 19(,4):530-7.

14. Ramchandran L. y Vasiljevic. Whey Processing in Membrane Processing: Dairy and Beverage Applications. (ed A. Y. Tamime), Blackwell Publishing Ltd., Oxford, UK. DEC 2012, doi: 10.1002/9781118457009.ch92013: 193-207. 14

15. Piotr Rucinsky. Dairy and products annual. Foreing Agricultural Service, USDA. GAIN Report Number: PL1218. 2012.

16. Wang $Y$, Li S. Worldwide trends in dairy production and consumption and calcium intake: is promoting consumption of dairy products a sustainable solution for inadequate calcium intake?., Food Nutr Bull. 2008; 29(3): 172-85.

17. Kranz S, Lin PJ, Wagstaff DA. Children's dairy intake in the United States: too little, too fat? J Pediatr. 2007;151(6):642-6.

18. Wang, Youfa. Fast-Food Consumption: Its Association with Food Prices and Dietary Quality. En Diet Quality. Springer New York, Nutr. Hecolth. 2013. p. 141-50.

19. I. Lenoir-Wijnkoopa J. Jonesa, R. Uauya, L. Segala and J. Milnera. Nutrition economics - food as an ally of public health., British J Nutr. 2013;109: 777-84.

20. Léon Guéguen, MsScAgr and Alain Pointillart, DVM.The Bioavailability of Dietary Calcium. J Am Coll Nutr . 2000; 19 (Supl. 2): 119S-36S.

21. M.H. Abd El-Salam, Safinaz El-Shibiny \& Aida Salem. Factors Affecting the Functional Properties of Whey Protein Products a Review. Food Rev Internat. 2009;25 (3) 251-70.

22. Jan Kobukowski, Jerzy Szpendowski, Joanna Salmanowicz. Bioavailability of some microelements from post-ultrafiltration permeates and whey. Pol. J. Food Nutr, Sci. 2006; 15/56, (SI 1): 95-100.

23. G. S. Ranhotra, J. A. Gelroth, S.D. Leinen, B.S., and A. Rao. Bioavailability of calcium in a high calci um whey fraction. Nutr Res.1997;17(11/12): 1663-7.

24. Yasuhiro Toba, Yukihiro Takada, Miyako Tanaka, Seiichiro Aoe.Comparison of the effects of milk components and calcium source on calcium bioavailability in growing male rats. Nutrition Res. 1999; 19 (3); 449-59.

25. Bauman D, Mather I, Wall R, Lock A. Major advances associated with the biosynthesis of milk. J Dairy Sci. 2006; 89:1235-43.

26. Carlos Alvarado Carrasco, Marisa Guerra. Lactosuero como fuente de péptidos bioactivos. An Venez Nutr. 2010;231: 42-9.

27. Madureira AR, Tavares T, Gomes AM, Pintado ME, Malcata FX. Invited review: Physiological properties of bioactive peptides obtained from whey proteins. I Dairy Sci. 2010; 93: 437-55.

28. Shrikant Sharma, Raqhuendar SIngh, Shashank Rana. Bioactive peptides: A Review. Int. J. Bioautomation. 2012, 15: 223-50.

29. Aheri, A., Sabeena Farvin, K. H., Jacobsen, C., \& Baron,
C. P. Antioxidant activities and functional properties of protein and peptide fractions isolated from salted herring brine. Food Chem. 2014:142: 318-26.

30. Tavares, Tânia G. y Malcata, F. Xavier.Whey proteins as source of bioactive peptides against hypertension. In Bioactive food peptides in health and disease (ed: Blanca Hernandez-Ledesma and Chia-Chien Hsieh), In Tech. Jan 2013, DOI: $10.5772 / 52680$.

31. Ronald D. Emkey, MD. Calcium Metabolism and Correcting Calcium Deficiencies. Endocrinol Metab Clin North Am. 2012; 41:527-56.

32. Pansu D, Bronner F. Nutritional aspects of calcium absorption. J Nutr. 1999;129: 9-12.

33. Pawel R. Kiela, James F. Collins, Fayez K. Ghishan. Molecular Mechanisms of Intestinal Transport of Calcium, Phosphate, and Magnesium. Physiology of the Gastrointestinal Tract (Fifth Edition). s.I. : Academic Press, 2012; 2, Chapter 70. 1877-919.

34. Bronner, F. Recent developments in intestinal calcium absorption. Nutr Rev 2009; 67(2): 65-123.

35. Ken Kato, Yasuhiro Toba, Hiroaki Matsuyama, Takayoshi Aoki, Seiichiro Aoe and Yukihiro Takada. A Novel Type of Milk Calcium Has Higher Calcium Bioavailability Compared with the Hydroxyapatite Type of Milk calcium. J Nutr Sci Vitaminol. 2002; 48:390-4.

36. Hae-Soo Kwaka, Won-Jae Lee, Mee-Ryung Lee. Revisiting lactose as an enhancer of calcium absorption. Internat. Dairy J. 2012; 22 (2): 147-51.

37. Y.V. Yuan, D.D. Kitts, T. Nagasawa. The Effect of Lactose and Fermentation Products on Paracellular Calcium Absorption and Femur Biomechanics in Rats. Canadian Institute Food Sci Technol J. 1991; 24 (1-2): 74-80.

38. Armin Zittermann, Petra Bock, Christian Drummer, Kerstin Scheld, Martina Heer, Peter Stehle. Lactose does not enhance calcium bioavailability in lactose-tolerant, healthy adults. Am J Clin Nutr. 2000;71: 931-6.

39. FW, Lengemann.The site of action of lactose in the enhancement of calcium utilization. I Nutr. 1959; 69:23-7.

40. Buzinaro EF, Almeida RN, Mazeto GM. Bioavailability of dietary calcium. Arq Bras Endocrinol Metabol. 2006;50: 852-61.

41. Pérez AV, Picotto $G$, Carpentieri AR, Rivoira MA, Peralta López ME, Tolosa de Talamoni NG. Minireview on regulation of intestinal calcium absorption. Emphasis on molecular mechanisms of transcellular pathway. Digestion. 2008;77: 22-34. doi: 10.1159/000116623.

42. Charley $P$, Saltman P. Chelation of calcium by lactose: its role intransport mechanisms. Science.1963;139:1205-6.

43. Fournier $P$, Dupuis $Y$, Fournier A. L'absorption, par le rat, du calcium de divers laits, examine'e en fonction de leur teneur en phosphore total et en lactose. Ann Nutr Alim.1975; 29: 424-38.

44. Effect of lactose or its component sugars on jejunal calcium absorption in adult man. Schuette SA, Knowles JB, Ford HE. 5, Am J Clin Nutr. 1989, 50, 1084-7.

45. Armin Zittermann, Petra Bock, Christian Drummer, Kerstin Scheld,Martina Heer, and Peter Stehle. Lactose does not enhance calcium bioavailability in lactose-tolerant, healthy adult. Am J Clin Nutr. 2000;71: 931-6.

46. Brink EJ, Beresteijn van CH, Dekker PR. Urinary excretion of magnesium and calcium as an index of absorption is not affected by lactose intake in healthy adults. Br J Nutr. 1993;69:863-70.

47. Cochet $B$, Jung $A$, Griessen $M$, Bartholdi $P$, Schaller $P, D o-$ 
nath A.Effects of lactose on intestinal calcium absorption in normal and lactase-deficient subjects. Gastroenterol. 1983; 84(5 Pt 1 ):935-40.

48. Tremaine, W. J., Newcomer, A. D., \& McGill, D. B.Calcium absorption from milk in lactase-deficient and lactasesufficient adults. Digestive Diseases Sci. 1986; 31: 376-8.

49. Smith TM, Kolars JC, Savaiano DA, Levitt MD.Absorption of calcium from milk and yogurt. Am J Clin Nutr.1985;42: 1197-200.

50. Wynckel A, Jaisser F, Wong T, Drüeke T, Chanard J.Intestinal absorption of calcium from yogurt in lactase-deficient subjects. Reprod Nutr Dev.1991; 31: 411-8.

51. Griessen $M$, Cochet $B$, Infante $F$, Jung $A$, Bartholdi $P_{,}$ Donath A,Loizeau $E$, Courvoisier B:Calcium absorption from milk in lactase-deficient subjects. Am J Clin Nutr. 1989;49:377-84

52. Medeiros LC, Lederman HM, de Morais MB.Lactose malabsorption, calcium intake, and bone mass in children and adolescents. J Pediatr Gastroenterol Nutr.2012;54: 204-9. doi: 10.1097/MPG.0b013e3182380604.

53. Parra MD, Martínez de Morentin BE, Cobo JM, LenoirWijnkoop I, Martínez JA. Acute calcium assimilation from fresh or pasteurized yoghurt depending on the lactose digestibility status. J. Am Coll Nutr. 2007; 26 (3): 288-94

54. Figueroa-Hernández, C., Cruz-Guerrero, A., RodríguezSerrano, G., Gómez-Ruiz, L., García-Garibay, M., \& Jiménez-Guzmán.Producciòn de pèptidos fijadores de calcio y hierro por Lactococcus lactis subsp. cremoris NCFB 712. Rev Mexicana Ingeniería Química. 2012; 11: 259-67.

55. Saral-Simietana Maria, zdunczyk Zenon, wronkawska Malgarzata, Juskewiccz Jeizy, Zander Lidia. Mineral composition and bioavailability of calcium and phosphorus from acid whey concentrated by various membrane process. J. Elem.2012; Vol. Doi 10.5601/Jelem 18.1.10: 115-25.

56. Morita, Y., Ono-Ohmachi, A., Higurashi, S., Matsuyama, H., Serizawa, A., \& Takeya, T. The bone-strengthening activity of milk basic protein is not dependent on lactoferrin. Internat Dairy J. 2012;27: 40-6.

57. M.C. Krugera, R.C. Poulsena, L. Schollumb, N. Haggartyb, S. Ramb, K. Palmanob A comparison between acidic and basic protein fractions from whey or milk for reduction of bone loss in the ovariectomised rat. Internat Dairy J. 2006;16:1149-56.

58. Yukihiro Takada, Hiroaki Matsuyama, Ken Kato, Naomichi Kobayashi,Jun-ichi Yamamura, Masatoshi Yahiro,et al. MILK WHEY PROTEIN ENHANCES THE BONE BREAKINC FORCE IN OVARIECTOMIZED RATS. Nutrit Res. 1997;17: 1709-20.
59. Denis Barclay, Rolf Felix, Fiona Ginty, Roman Muhlbauer, Jean-Richard Neeser, Cavin Elizabeth Offord, Heidi Tullberg-Reinert,. Milk protein hydrolysate for addressing a bone or dental disorder. WO2000049885 A1 31 de Ago de 2000

60. Soral-Esmietana, M., Zduńczyk, Z., Wronkowska, M., Juœkiewicz, J., \& Zander, L. Mineral composition and bioavailability of calcium and phosphorus from acid whey concentrated by various membrane processes. Reports issued by the Polish Society for Magnesium Research and University of Warmia and Mazury in Olsztyn. 2013: p115.

61. M.H. Abd El-Salama, Safinaz El-Shibinya \& Aida Salemb. Factors Affecting the Functional Properties of Whey Protein Products: A Review. Food Rev Internat. 2009; 25: 251-70.

62. Kłobukowski, J., Szpendowski, J. y Salmanowicz, J Bioavailability of some macroelements from post-ultrafiltration permeates and whey. Polish J Food Nutr Sci. 2006;15 (1): 95-100.

63. Román, A., y otros, y otros.Partial demineralization and concentration of acid whey by nanofiltration combined with diafiltration. J Desalination. 2009;241:288-95 .

64. Walzem R, Dillard C, German J. Whey components: millennia of evolution create functionalities for mamalian nutrition: what we know and what we may be overlooking. Crit Rev Food Sci. 2002; 42: 353-75.

65. Anesar, P., J. Kennedy, D. Gandhi and K. Bunko P. Bio utilization of whey for lactic. Acid production Food Chem. 2007;105: 1-14.

66. Baro, L., J. Jiménez, A. Martínez y J. Bouza.Péptidos y proteínas de la leche con propiedades funcionales. Ars. Pharmaceutica. 2001; 42(3-4): 135-45.

67. Hinrichs R., J. Gotz, M. Noll, A. Wolfschoon, H. Eibeland H. Weisser.Characterization of different treated whey protein concentrates by means of low resolution nuclear magnetic resonance. Internat Dairy J. 2004;14(9): 817-27.

68. Bordin G, Cordeiro-Raposo F, de la Calle B, Rodriguez A. Identification and quantification of major bovine milk proteins by liquid chromatography. J Chromatogr A . 2001;928: 63-76.

69. Londoño, M. Aprovechamiento del suero ácido de queso doble crema para la elaboración de quesillo utilizando tres métodos de complementación de acidez con tres ácidos orgánicos. Perspectivas Nutr. Humana. 2006; 16:11-20

70. Madureira, A. R., C. I. Pereira, A. M. P. Gomes, M. E. Pintado. Bovine whey proteins-Overview on the main biological properties. Food Res Int. 2007;40: 1197-21.

71. De Wit, J. N. Nutritional and functional characteristics of whey proteins in food products. J Dairy Sci.1998; 81: 597-608. 